\title{
NOTAS SOBRE EL RETRACTO ADMINISTRATIVO Y SU REGIMEN JURIDICO. SITUACION DEL AYUNTAMIENTO BENEFICIARIO
}

\author{
POR \\ Juan antonio Alvarez Martín \\ Secretario de Administración Local
}

SUMARIO: I. Naturaleza jurídica del retracto legal. II. Aplicabilidad de la normativa de expropiación forzosa en supuestos de retracto legal de carácter administrativo. III. Situación del Ayuntamiento. IV. Consignación del justiprecio. V. Ocupación de la finca: Toma de posesión. VI. Inscripción en el Registro de la Propiedad. VII. Respeto al propietario en la posesión del bien.

\section{NATURALEZA JURIDICA DEL RETRACTO LEGAL}

Es docrina pacífica que el retracto puede definirse como «el derecho que por virtud de la Ley compete al vendedor o a una tercera persona que no interviniera en el contrato para adquirir la cosa vendida subrogándose en el lugar y derecho del comprador"(CASTÁN). Afecta al propietario con tal intensidad que restringe su libertad para elegir la persona que por compraventa u otro título traslativo haya adquirido su cosa (STS 6 de marzo 1971), actuando siempre con la máxima eficacia frente a los terceros, hasta el punto que quedan inertes los enérgicos resortes de defensa que la inscripción registral lleva consigo. (Resolución 0 . General de Registro 4 de octubre de 1982.)

Es la causa de la resolución de la venta (Código Civil art. 1506), quedando sin embargo subsistente la enajenación realizada salvo lo que se refiere a la diferencia de personas, pues el retrayente sustituye al comprador, pero sin introducir alteración alguna en las condiciones estipuladas que forzosamente habrán de respetarse (STS 12 noviembre 1964).

Es el retracto legal, en suma, una importante restricción de las facultades dominicales. Limitación que tiene su origen en la Ley, constriñendo el amplio marco que define la propiedad en el artículo 348 del Código Civil, y con una fuerza tal que por mandato del artículo 37 de la Ley Hipotecaria queda desprovisto de operatividad la protección del artículo 34 de la misma Ley a favor del tercero que haya inscrito los títulos de sus respectivos derechos. 
II. APLICABILIDAD DE LA NORMATIVA DE EXPROPIACION FORZOSA EN SUPUESTOS DE RETRACTO LEGAL DE CARACTER ADMINISTRATIVO

Independientemente de la normativa específica en que se funda la Resolución por la que se retrae el bien en concreto, la aplicabilidad de la normativa de expropiación forzosa (Ley de 16 de diciembre de 1954 y Reglamento de 26 de abril de 1957) ha de llevarse más allá de los artículos 81 de la Ley y 97 a 100 de su Reglamento, relativos al retracto.

La fórmula extensa con que se comprende la expropiación forzosa desde el frontispicio de la propia Ley (art. 1.1 de la LEF y 1.1 y 2 del REF) hacen obligada la remisión a los artículos 1. de la Ley de Expropiación Forzosa y de su Reglamento, de los que se deriva que expropiación forzosa es toda intervención administrativa que conlleve privación singular de propiedad, derechos o intereses patrimoniales legítimos, ya implique venta, permuta, etc. El artículo 2 del citado Reglamento establece que las expropiaciones no reguladas por los Títulos III y IV de la Ley de Expropiación Forzosa que estén autorizadas por otra Ley se regirán: 1.ㅇ por sus disposiciones especiales; 2. por la Ley General y su Reglamento.

En consecuencia, cuando la normativa en que se funde el retracto carezca de disposiciones especiales sobre consignación del precio y ocupación del inmueble, resultan de aplicación el Capítulo IV del Título II de la Ley de Expropiación Forzosa. y su Reglamento.

\section{SITUACION DEL AYUNTAMIENTO}

a) Es beneficiario.-Esta condición es plenamente reconocida por la normativa de Expropiación Forzosa en los artículos 2.2 de la LEF de $16 /$ XII/54 y 3.1 de su Reglamento.

- En tanto que el beneficiario, además de las obligaciones que le asigne el número 1 del artículo 5. o del Reglamento de Expropiación Forzosa, tiene atribuido las facultades y obligaciones recogidas en el número 2 del mismo artículo $y$ concretamente:

- Art. 5. 2 - 5. o. Pagar o consignar, en su caso, la cantidad fijada como justo precio.

- Por su parte, como mantiene reiterada jurisprudencia del Tribunal Supremo (basta citar la de 16 de octubre de 1978), para tener la condición de beneficiario es imprescindible que concurra también el requisito de ser el adquirente del bien expropiado. 
b) Obligación del Ayuntamiento a pagar. - Existe tal obligación en tanto que beneficiario.

Su régimen legal se contempla en los artículos 48 y siguientes de la Ley de Expropiación Forzosa y 48 y siguientes de su Reglamento.

El pago ha de verificarse en dinero $y$, previa acta que se levantará ante el alcalde del término en que radiquen los bienes, a quienes figuren como dueños de la cosa. Las incidencias del pago se reflejarán en el acta que oportunamente se levante.

Advierte el artículo 49.2 del Reglamento que en el día y hora y lugar señalados se reunirá el alcalde, el representante del expropiante o delegado autorizado, el pagador, el secretario del Ayuntamiento y los interesados que hubieran acudido al llamamiento.

En cualquier caso, el pago de precio está exento de toda clase de gastos, impuestos, gravámenes o arbitrios (LEF art. 49).

\section{CONSIGNACION DEL JUSTIPRECIO}

Lo ordena el artículo 50 de la Ley y 51 de su Reglamento, para los supuestos en que el propietario rehúse recibir el precio, exista litigio o cuestión entre el interesado y la Administración, o simplemente no concurra al acto de pago. La consignación ha de hacerse en la Caja General de Depósito en metálico y en concepto de depósito necesario a disposición del expropiado.

No obstante, la mera consignación no tiene efectos liberatorios. La jurisprudencia del Tribunal Supremo (SS 10/10/79; 23 de abril 1980; 20 de octubre 1980) mantiene, en base a los artículos 1.452, 1.505 y 1.176 del C.C. en relación con el artículo 50 LEF y 51 de su Reglamento, como requisito para que la consignación opere efectos vinculantes y liberatorios, lo siguiente:

1.- Que se acredite la actitud pasiva o aquietamiento del acreedor o expropiado en el percibo del justo precio. Bien por hacerse el ofrecimiento de pago sin aceptarlo o citación en forma para su efectividad sin comparecer, rehusando en consecuencia a su percepción.

2. - Que el propietario de los bienes expropiados tenga conocimiento de la consignación, puesto que es exigencia ineludible para que pueda acudirse a ese medio liberatorio para el acreedor, que la consignación significa.

3. - La consignación, en tanto que acto administrativo requiere para su completa eficacia, de conformidad con el artículo 79 de la Ley de Procedimiento Administrativo de 17 de julio de 1958, y artículo 59 de la Ley Reguladora de la Jurisdicción Contencioso Administrativa de 27 de diciembre de 1956, la notificación o publicación en forma. 


\section{OCUPACION DE LA FINCA: TOMA DE POSESION}

Establece el artículo 51 de la Ley de Expropiación Forzosa que hecho efectivo el justo precio o consignado en la forma prevista en el artículo 50, podrá ocuparse la finca por vía administrativa.

En desarrollo de estos preceptos el Reglamento de la Ley de Expropiación Forzosa de 26 de abril de 1957 dedica los artículos 52 al 55 .

El Régimen jurídico de la toma de posesión viene determinado por:

- La expropiación forzosa produce la extinción de los arrendamientos y de cualesquiera otros derechos relativos a la posesión y ocupación de los bienes expropiados (Rgto. art. 52.1).

- Previo pago consignación, la autoridad a quien corresponda notificará a los ocupantes de la finca expropiada del plazo en que deben desalojarla, respetando en cualquier caso los plazos mínimos señalados en la Ley de Arrendamientos Urbanos de 24 de diciembre de 1964, artículos 142 al 152; y artículos 1.571 a 1.582 de la Ley de Enjuiciamiento Civil, conforme a la redacción dada a estos artículos por la Ley $46 / 76$ de 23 de julio.

- Los desahucios y alzamientos que exijan la ocupación tendrán carácter administrativo. En este sentido es de considerar el Título II «Del desahucio por vía administrativa», del Reglamento de bienes de las Entidades Locales aprobado por Real Decreto 1372/86 de 13 de junio («BOE» de 7 de julio).

- La ocupación requiere además, la confección de un «Acta de Ocupación». Tratándose como es el caso de bienes inscribibles en el Registro de la Propiedad, dicha acta ha de contener las prevenciones siguientes:

a) Nombre, apellidos y estado civil del beneficiario, caso de ser persona natural. Si se trata de persona jurídica, la denominación con que fuese conocida, su domicilio así como el nombre y circunstancia de las personas que en su representación intervengan en el acto de ocupación.

b) Las mismas circunstancias de la persona o personas que, según el acta de pago, reciban el justiprecio. Si tuvo lugar la consignación, la razón por la que se llevó ésta a cabo conforme al artículo 51 del Reglamento Expropiación Forzosa.

c) Naturaleza, situación y linderos de los bienes inmuebles objetos de la expropiación o a los cuales afecte el derecho que deba inscribirse, o cuya inscripción cancele, y su medida superficial. 
d) Naturaleza y extensión del derecho a que la expropiación se refiere.

e) Obra o servicio que motivó la expropiación.

En todo caso, el acto de ocupación es el documento oficial que concreta y delimita físicamente el bien que se expropia (STS 24 de enero de 1979).

\section{INSCRIPCION EN EL REGISTRO DE LA PROPIEDAD}

Su régimen jurídico se contempla en los artículos 53 de la Ley de Expropiación Forzosa y 60 y 62 de su Reglamento.

Cosntituyen título bastante para la inscripción en el Registro de la Propiedad el Acta de Pago acompañada de la correspondiente de ocupación. En su caso el justificante de la consignación del precio o el correspondiente resguardo de depósito surtirán iguales efectos que el acta de pago (art. 53 de LEF).

La solicitud de inscripción le corresponde al expropiante o al beneficiario.

No obstante, durante el expediente de expropiación, los asientos derivados de dicho procedimiento han de practicarse por el señor Registrador de la Propiedad conforme a lo dispuesto en el artículo 32 del Reglamento Hipotecario de 14 de febrero de 1947, redactado conforme a lo dispuesto por Decreto 393/59, de 17 de marzo. Las normas de dicho artículo son:

1. «Los registradores harán constar, en su caso, por notas al margen de las inscripciones correspondientes, que han expedido la certificación de dominio y cargas a efectos de la expropiación e indicarán su fecha y el procedimiento de que se trate. Estas notas se cancelarán por caducidad transcurridos tres años desde su fecha, si en el Registro no consta algún nuevo asiento relacionado con el mismo expediente.

2. Para que los títulos de expropiación puedan inscribirse, si se trata de fincas o derechos inscritos, el expediente deberá entenderse con el titular registral o quien justifique ser su causahabiente, por sí o debidamente representado, en la forma prevenida por la legislación especial, sin perjuicio de la intervención de otros interesados, si los hubiere.

3. Podrá extenderse anotación preventiva a favor del expropiante o beneficiario mediante el acta previa a la ocupación y el resguardo de depósito provisional. La anotación tendrá la duración señalada en el artículo 86 de la Ley y se convertirá en inscripción mediante el documento que acredite el pago o la consignación del justo precio, con el acta de ocupación. 
4. Será título inscribible a favor del expropiante o beneficiario el acta en que consten el pago y la ocupación, o solamente el acta de ocupación, acompañada en este caso del documento que acredite la consignación del justo precio o del correspondiente resguardo de depósito del mismo. En virtud de dichos títulos se practicará, en su caso, la inmatriculación. A los efectos de la inscripción, se entenderá fijado definitivamente el justo precio cuando, por no haber acuerdo, haya sido determinado aquél por el Jurado Provincial de Expropiaciones o el organismo competente con arreglo a las disposiciones especiales.

5. El dominio y las cargas, gravámenes, derechos reales y limitaciones de toda clase, inscritos con posterioridad a la fecha de la nota marginal a que se refiere este artículo, se cancelarán al practicarse la inscripción a favor del expropiante o beneficiario y en virtud del mismo título, aunque los interesados no hayan sido parte en el expediente, para cuya cancelación bastará su expresión genérica. Para que puedan cancelarse los asientos de fecha anterior a dicha nota deberá constar que los interesados han sido citados en forma legal y que concurrieron por sí o debidamente representados al pago, o que se consignó el precio o la parte necesaria del mismo, según los casos. En el título se determinarán los asientos que deban cancelarse y subsistir con referencia a los datos registrales.

6. Los asientos contendrán las circunstancias prevenidas para la inscripción en la legislación hipotecaria y las necesarias según la legislación especial. Si no pudiera hacerse constar alguna circunstancia se expresará así en el título y, en su caso, en la inscripción.»

\section{RESPETO AL PROPIETARIO EN LA POSESION DEL BIEN}

En tanto se hace efectivo el precio de la cosa o bien sobre el que se ejercita el retracto, se respetará al propietario en la posesión del mismo (art. 99 REF). 